\title{
Judicialização da medicina e o impacto orçamentário na administração pública: uma abordagem Médico-Legal
}

\section{Judicialization of Medicine and the Budgetary Impact on Public Administration: A Medicolegal Approach}

\author{
Otto Chaves $^{1}$, Talita Zerbini ${ }^{2}$
}

DOI: http://dx.doi.org/10.11606/issn.2317-2770.v22i2p58-65

\begin{abstract}
Chaves O, Zerbini T. Judicialização da medicina e o impacto orçamentário na administração pública: uma abordagem Médico-Legal. Saúde, Ética \& Justiça. 2017;22(2):58-65.

RESUMO: O presente estudo analisa as implicações decorrentes da judicialização da Medicina no orçamento da administração pública de saúde. Objetiva pontuar o papel da medicina legal no fenômeno da judicialização da saúde, mediante revisão bibliográfica e sistematização do material levantado. O método utilizado na pesquisa consistiu em uma revisão da literatura, na qual buscou-se observar a tendência do Poder Judiciário brasileiro e suas implicações nas políticas de saúde pública, na medida em que a Constituição da República de 1988 impõe ao Estado o dever de promover a saúde de forma gratuita e universal. Foram analisados os dados dos portais do Governo Federal, especificamente Portarias, Comunicados, Notas Técnicas e julgados, emitidos respectivamente pelo Conselho Nacional de Justiça, Ministério da Saúde, Advocacia Geral da União e Supremo Tribunal Federal. Os resultados mostram que a judicialização da saúde vem impactando o orçamento destinado à saúde de maneira vultuosa, de tal forma que o sistema de saúde poderá não ter condições de sustentar-se por muito tempo. Conclui-se que não é possível apontar os rumos exatos que a judicialização tomará no Brasil. Observa-se uma tendência de disponibilizar ferramentas para a análise técnica de demandas que são judicializadas. A contribuição da medicina legal nesse respaldo técnico, seja através da emissão de laudos, pareceres ou atuação em comissões, ajuda o Judiciário a prevenir fraudes envolvendo a prestação de serviços de saúde, otimizando, assim, o gasto dos cofres públicos decorrente do ativismo judicial.
\end{abstract}

DESCRITORES: Direito à Saúde; Decisões Judiciais; Políticas Públicas de Saúde.

\footnotetext{
1. Instituto Médico-Legal - Polícia Civil do Estado de Minas Gerais -R. Nícias Continentino, 1291 - Nova Gameleira, Belo Horizonte/MG. 30510-160. E-mail: otto@smpericias.com.br

2. Faculdade de Ciências Médicas da Santa Casa, Central de Convênios da Fundação ABC, Instituto Médico Legal de São Paulo. E-mail: tazerbini@yahoo.com.br
} 


\section{INTRODUÇÃO}

A Constituição da República Federativa do Brasil, de 1988 (CR/88), inovou ao reconhecer a saúde como direito fundamental, haja vista que inexistiu em constituições anteriores a previsão expressa da garantia de acesso aos serviços de saúde de forma universal e igualitária ${ }^{1}$.

Assim, consoante elencado no art. $6^{\circ}$, da CR/88, os direitos sociais fundamentais são a educação, a saúde, o trabalho, o lazer, a segurança, a previdência social, a proteção à maternidade e à infância. Adiante, no art. 196, o texto constitucional é enfático ao reconhecer a saúde como direito de todos e dever do Estado ${ }^{1}$.

Não obstante a obrigação daAdministração Pública em fazer cumprir as determinações constitucionais, especialmente no que tange às garantias de acesso à Saúde no Brasil, sabe-se que tal cumprimento é deficitário e, por isso, tem-se tornado bastante comum recorrer ao Poder Judiciário como alternativa para a obtenção de medicamento ou tratamento no Sistema Único de Saúde $(\mathrm{SUS})^{2}$

Nesse sentido, no que se refere ao impacto nos cofres da União, que também será campo de análise do presente estudo, observa-se o aumento exponencial nos gastos na saúde pública para cumprir ordens judiciais que determinam a aquisição de medicamentos, equipamentos, insumos e realização de cirurgias não previstas pela medicina assistencial ${ }^{2}$.

$\mathrm{O}$ confronto de importância entre o direito individualizado e aquele planejado para atender à coletividade é, na grande maioria dos casos, o mote que serve como palco das discussões mais acaloradas no âmbito jurídico, pois, de um lado, há o cidadão necessitado, possuidor de um direito constitucional ao tratamento de saúde e, do outro lado, há o orçamento público e a coletividade, beneficiária dos investimentos não individualizados ${ }^{3}$.

O papel da análise técnica de cada demanda, mediante a perícia médico-legal, é de fundamental importância para avaliar a necessidade do tratamento pleiteado, bem como da possibilidade de substituí-lo por outro que seja fornecido gratuitamente pelo SUS ${ }^{3}$.

Inclusive, noticiou-se que o Conselho Nacional de Justiça (CNJ) criou um fórum nacional voltado para o assunto, propondo um projeto em parceria com a União para a capacitação de núcleos técnicos nos estados, que deem suporte aos magistrados em suas decisões. Uma das apostas para diminuir o problema é a criação de varas únicas de saúde nos estados, com juízes aparelhados com embasamento técnico e visão ampla do sistema ${ }^{4}$.

\section{MÉTODO}

O presente estudo analisa as repercussões das demandas judiciais de saúde na efetivação das políticas públicas, inclusive o impacto no orçamento da administração pública, além de pontuar o papel da Medicina Legal no estudo dessas questões.

Dessa forma, foi realizado levantamento de dados online em sites do Governo Federal, quais sejam, do Conselho Nacional de Justiça, Ministério da Saúde, Advocacia Geral da União e Supremo Tribunal Federal, no que tange respectivamente a Portarias, Comunicados, Notas Técnicas, Despachos e reportagens, além de pesquisa de jurisprudências disponíveis em sites do Poder Judiciário, utilizando os termos "Judicialização Saúde" e "Ativismo Judicial" no campo disponibilizado para pesquisa específica, no período de junho de 2010 a junho de 2017.

\section{DELINEAMENTO CONCEITUAL E RESULTADOS}

Utilizando os termos supracitados, no site do Conselho Nacional de Justiça ${ }^{5}$ foram encontrados 180 resultados, entre Atos Normativos e notícias; no site do Ministério da Saúde ${ }^{6}, 50$ resultados; no site da Advocacia Geral da União 7,104 resultados, entre notícias, eventos e páginas internas; no site do Supremo Tribunal Federal ${ }^{8}$ foram encontradas 27 notícias.

Foram selecionados, para utilização no presente estudo, Portarias, Comunicados, Notas Técnicas, Despachos e reportagens que tratam diretamente da judicialização da saúde, no que tange à capacitação do judiciário, impacto orçamentário e articulação entre o judiciário, o executivo e a sociedade civil. Não foram analisados despachos e outros documentos que tratam de casos individuais, haja vista não serem objetivo dessa análise.

\section{Saúde como direito social, do homem e fundamental}

Sob um prisma filosófico, direito fundamental é o direito atribuível a qualquer ser humano, pelo simples fato de ele existir racionalmente. Para o Direito contemporâneo, entretanto, direito fundamental possui um sentido mais concreto, qual seja, daquele direito positivado e reconhecido como essencial no ordenamento jurídico interno e constitucional de determinado Estado.

Nesse sentido, considera-se que a saúde, no Brasil, após a promulgação da $\mathrm{CR} / 88$, passou a figurar como direito fundamental, objeto de tutela e garantia por parte do poder público ${ }^{1}$.

Em razão desse status, diz-se que a saúde integra o mínimo existencial, necessário à dignidade da pessoa humana, para o que o ordenamento atribui eficácia integral e aplicabilidade imediata. Esclarecendo, o professor constitucionalista José Afonso da Silva, leciona que "as normas constitucionais que enunciam os direitos 
individuais são de aplicabilidade imediata e direta; sua eficácia não depende da intermediação do legislador"’.

De modo que, resta claro, principalmente em virtude da norma contida do art. 196 da $\mathrm{CR} / 88$, que o direito à saúde exige do Estado uma ação positiva e prestacional ${ }^{1}$. É o poder público quem tem que se organizar estruturalmente e criar instrumentos de efetivação do acesso aos tratamentos de saúde.

Além disso, ressalta-se, a saúde é direito protegido por diversos tratados internacionais, dos quais o Brasil é signatário, tais como a Convenção Americana sobre Direitos Humanos ${ }^{10}$, o Pacto Internacional dos Direitos Econômicos, Sociais e Culturais ${ }^{11}$ e a Convenção sobre os Direitos da Criança ${ }^{12}$.

\section{Judicialização da medicina}

É justamente porque a saúde está inserida nesse contexto - de direito fundamental dotado de aplicabilidade imediata e dimensão positiva - que se tem assegurado ao cidadão a possibilidade de o mesmo exigir do Estado o seu cumprimento, o que tem sido feito, largamente, por meio da propositura de processos judiciais.

Do crescente chamamento do Poder Judiciário para dirimir as questões relativas ao direito à saúde, observaram-se os fenômenos jurídicos cunhados de judicialização das políticas públicas e ativismo judicial $^{13}$.

A judicialização se constitui quando o Judiciário é provocado para tutelar certos direitos, acerca dos quais as outras esferas estatais (executivo e legislativo) se mostraram omissas ou insatisfatórias. E, por sua vez, o ativismo judicial (na acepção que importa ao presente estudo) é a exteriorização da vontade, uma escolha do magistrado em como interpretar e aplicar as normas constitucionais.

Sobre os conceitos ora apresentados, bastante didática é a lição de Luís Roberto Barroso ${ }^{14}$. Vejamos:

"A judicialização e o ativismo judicial são primos. Vêm, portanto, da mesma família, frequentam os mesmos lugares, mas não têm as mesmas origens. Não são gerados, a rigor, pelas mesmas causas imediatas. A judicialização, no contexto brasileiro, é um fato, uma circunstância que decorre do modelo constitucional que se adotou, e não um exercício deliberado de vontade política. Em todos os casos referidos acima, o Judiciário decidiu porque era o que lhe cabia fazer, sem alternativa. Se uma norma constitucional permite que dela se deduza uma pretensão, subjetiva ou objetiva, ao juiz cabe dela conhecer, decidindo a matéria. Já o ativismo judicial é uma atitude, a escolha de um modo específico e proativo de interpretar a Constituição, expandindo o seu sentido e alcance. Normalmente ele se instala em situações de retração do Poder Legislativo, de um certo descolamento entre a classe política e a sociedade civil, impedindo que as demanda sociais sejam atendidas de maneira efetiva."

Portanto, em síntese, a judicialização das políticas públicas se aperfeiçoa pela posição de destaque em que figura o Poder Judiciário, em razão do crescimento numérico de processos e, consequentemente, de resolução de casos sobre determinados direitos sociais. Enquanto que o ativismo judicial ocorre quando, de fato, o juiz norteia sua conduta para concretizar seu fim institucional, acarretando, para tanto, a ampliação do alcance da norma interpretada.

Insta salientar, entretanto, que no âmbito do direito à saúde, a distinção entre a judicialização deste direito e o ativismo judicial não é tarefa fácil. Isso porque a norma constitucional contida do art. 196 da CR/88 enquadra-se na classificação cunhada por José Afonso da Silva ${ }^{15}$ de norma definidora de conteúdo programático que, conforme consignado anteriormente, é dotada de aplicabilidade direta e imediata. Ou seja, tal norma não se preocupa, a priori, com a estrutura e a organização da administração pública ou dos poderes estatais, mas, sim, com a efetivação e o cumprimento do direito postulado na $\mathrm{CR} / 88$.

Logo, diante de casos peculiares como os que ocorrem na seara sanitária, tais como os pedidos urgentes de tratamentos para doenças raras e o fornecimento de medicamentos de alto custo, os magistrados, já inseridos no contexto da judicialização do direito à saúde, veem-se confrontados com a inevitabilidade de negar um direito constitucional pleiteado. Daí, então, é que se criam prestações e exigências muitas vezes não inclusas na programação orçamentária do ente político.

Os principais embates jurídicos sobre o tema da atuação do judiciário na efetivação dos direitos à saúde circunscrevem-se a esse ponto. Isto é, saber definir se e/ ou quando o ativismo é legítimo. Pois, sabe-se, o direito está garantido, mas está sendo corretamente interpretado e efetivado? Além disso, a judicialização está posta, e desta o Judiciário não pode se afastar, também por mandamento constitucional ${ }^{1}$.

Em análise específica sobre o assunto, Luís Roberto Barroso não nega a posição ativista do Judiciário, e diz mais, afirmando que em alguns casos o magistrado deveria não interferir na esfera de atuação dos outros poderes. Confira-se:

“(...) na categoria de ativismo mediante imposição de condutas ou de abstenções ao Poder Público, notadamente em matéria de políticas públicas, o exemplo mais notório provavelmente é o da distribuição de medicamentos e determinação de terapias mediante decisão judicial. (...) Todavia, nas Justiças estadual e federal em todo o país, multiplicamse decisões que condenam a União, o Estado ou o 
Município - por vezes, os três solidariamente - a custear medicamentos e terapias que não constam das listas e protocolos do Ministério da Saúde ou das secretarias estaduais e municipais. Em alguns casos, os tratamentos exigidos são experimentais ou devem ser realizados no exterior." p. $78^{14}$.

“(...) ao lado de intervenções necessárias e meritórias, tem havido uma profusão de decisões extravagantes ou emocionais em matéria de medicamentos e terapias, que põem em risco a própria continuidade das políticas públicas de saúde, desorganizando a atividade administrativa e comprometendo a alocação dos escassos recursos públicos.” p. $84^{14}$.

Em 19/04/2012, por ocasião da solenidade de posse do Ministro Carlos Ayres Britto na Presidência do Supremo Tribunal Federal e do Conselho Nacional de Justiça, o Ministro Celso de Mello ressaltou a preocupação da Suprema Corte com a questão que ora se expõe. Foram as suas considerações:

(...) Quando se registram omissões inconstitucionais doEstado, sempretãoilegítimas quãoprofundamente lesivas a direitos e liberdades fundamentais das pessoas, das instituições e da própria coletividade, torna-se justificável a intervenção do Judiciário, notadamente a desta Corte Suprema, para suprir incompreensíveis situações de inércia reveladas pelas instâncias de poder em que se pluraliza o aparelho estatal brasileiro. [...] Práticas de ativismo judicial, embora moderadamente desempenhadas pela Corte Suprema em momentos excepcionais, tornam-se uma necessidade institucional, quando os órgãos do Poder Público se omitem ou retardam, excessivamente, o cumprimento de obrigações a que estão sujeitos, ainda mais se se tiver presente que o Poder Judiciário, tratando-se de comportamentos estatais ofensivos à Constituição, não pode se reduzir a uma posição de pura passividade"16.

Conclui-se, por conseguinte, que a questão da judicialização e do ativismo judicial, no que tange às políticas públicas de saúde, é muito complexa. Os pensadores do Direito têm se esforçado para tentar estabelecer o que viria a ser uma equilibrada atuação do Judiciário. O cerne da questão é fazer a escolha do que é prioritário na prestação da saúde e, além disso, qual o ente público responsável por determinar o que é prioritário, onde os seus próprios recursos serão alocados e como as políticas públicas serão implementadas.

Por exemplo, tomando como base que o Brasil, consoante art. $1^{\circ}$, parágrafo único, da $\mathrm{CR} / 88$, adota $\mathrm{o}$ princípio da soberania popular ${ }^{1}$, exercida por meio de representantes eleitos diretamente pelo povo, deduz-se que as decisões acerca da efetividade do direito à saúde deviam ser estabelecidas pelo Legislativo. Assim, estarse-ia prestigiando o princípio democrático, o que não ocorre quando essas importantes decisões sobre políticas públicas sanitárias ficam relegadas somente ao campo das ordens judiciais.

Contudo, afastar irremediavelmente o Judiciário da efetivação dos direitos sociais é esvaziar por completo a eficácia das disposições constitucionais, com o risco de reduzir a Constituição de 1988 tão somente ao plano simbólico.

Entretanto, é impossível dissociar esse panorama jurídico da análise que se quer fazer, qual seja, a do impacto das decisões judiciais em demandas de saúde nos cofres da União, com a posterior exposição de como a medicina legal pode ser uma aliada do Judiciário, em tempos de judicialização da saúde.

Ciente de tais divergências no que tange à interpretação do direito constitucional à saúde, bem como dos fenômenos hoje existentes da judicialização e do ativismo judicial, passa-se, pois, ao tópico seguinte.

\section{Efeitos orçamentários da judicialização da saúde}

Em termos concretos, a judicialização das políticas públicas sanitárias é ocasionada porque centenas de milhares de brasileiros, individualmente, procuram um advogado e interpõem ações judiciais pleiteando que seja ordenado o cumprimento de determinada prestação de assistência à sua saúde. Tal assistência, por exemplo e, não raro, configura-se no fornecimento de fármacos de alto custo, não previstos na lista de medicamentos do SUS e muitas vezes não aprovados pela Agência Nacional de Vigilância Sanitária (ANVISA) ${ }^{17}$.

O Magistrado, então, depara-se com a demanda de um cidadão doente, possuidor de documentos médicos que lhe indicam o tratamento por aquele determinado fármaco, sem o qual, alega-se, corre sério risco de vida, mesmo não se tratando de uma emergência.

$\mathrm{Na}$ petição, é invocado o direito fundamental à saúde, previsto expressamente na $\mathrm{CR} / 88$ como direito de todos e dever do Estado. Assim, nesse tipo de ação, o que comumente acontece é que são expedidas ordens, muitas vezes em caráter liminar - antes da realização da perícia médica -, para que os entes da Administração Pública procedam ao fornecimento do remédio pleiteado.

Nesse típico exemplo, não são avaliadas as condições dos cofres públicos. E, pior, os julgadores não possuem conhecimento técnico médico para avaliar o custo-benefício da utilização do fármaco importado, de alto valor, em detrimento de outro medicamento disponível no SUS. Lembrando que essa análise deve ser feita num contexto de coletividade, pois há infindáveis ações com o mesmo pedido, e tantas outras pessoas, ainda mais necessitadas de tratamento de saúde, que não possuem acesso à Justiça.

Nesse sentido, tem-se que a falta de embasamento 
técnico no cumprimento das decisões judiciais pode levar ao desperdício de recursos públicos, uma vez que a aquisição dos medicamentos e insumos não é feita de maneira planejada e nem por meio de processo criterioso. É necessário buscar organização e aperfeiçoamento da análise técnica sanitária, de modo a não sobrecarregar um orçamento já subfinanciado ${ }^{18}$.

Para se ter uma estimativa do aumento da despesa da União, ocasionado por determinações judiciais em matéria de saúde, confiram-se os números: em 2010, foram R \$ 122,6 milhões; em 2014, o gasto chegou a R \$ 838,4 milhões ${ }^{19}$.

Em 2015, segundo dados do governo federal, os gastos do SUS para cumprimento de decisões judiciais foram de R \$ 1,013 bilhão ${ }^{20}$. E, deste numerário, cerca de $99 \%$ foram de processos que diziam respeito à compra de medicamentos ${ }^{20}$.

Vê-se, portanto, que de 2010 a 2015, houve um aumento de 500\% nos gastos do Ministério da Saúde com ações judiciais para aquisição de medicamentos, equipamentos, insumos, realização de cirurgias e depósitos judiciais ${ }^{21}$.

Os dados são alarmantes e servem para dimensionar o tamanho do problema: somente de janeiro a maio de 2016, o Ministério da Saúde gastou R\$ 693,7 milhões, forçado por processos judiciais. E a estimativa é que terminasse 2016 com um novo recorde, com a cifra de $\mathrm{R} \$ 1,6$ bilhão ${ }^{20}$, dado este ainda não liberado pela União até o presente estudo, realizado em junho de 2017.

Entretanto, deve-se lembrar que tais números são apenas a parte de uma equação bem mais complexa, pois quando há vidas em jogo, não se pode simplesmente limitar as despesas do Estado com saúde. O que se defende, por conseguinte, é que os investimentos na saúde comunitária e de base sejam aumentados, com a melhoria quantitativa e qualitativa dos serviços postos à disposição da sociedade - para que não seja necessário recorrer à Justiça - e, em concomitância, que seja aperfeiçoada a metodologia de trabalho do Judiciário, no que tange aos pedidos que envolvam tratamentos médicos.

Pois, o que se vê é que os magistrados acabam por determinar a execução de tratamentos e o fornecimento de medicamentos que não são oferecidos pelo SUS, e/ou que estão em fase experimental no exterior, até mesmo em casos em que ainda não houve a comprovação da eficácia do medicamento e não há a liberação pela ANVISA para utilização do medicamento no Brasil.

Assim, com uma demanda individual, gasta-se mais do que o previsto de investimento e repasse para determinado Município, por exemplo.

No estado de São Paulo, há dados que demonstram claramente como as determinações judiciais carecem de critérios técnicos e podem provocar uma consequência nefasta no orçamento público. Vejamos:

De 2010 a 2016, a Secretária de Estado da Saúde de São Paulo foi alvo de 79.557 ações para entrega de medicamentos, materiais de nutrição, entre outros itens ${ }^{22}$. Em 2015, o Estado recebeu 18.045 novas ações, contra 14.383 no ano anterior, 14.080 em 2013, $12.031 \mathrm{em}$ 2012, 11.633 em 2011 e 9.385 em 2010. Atualmente, a pasta cumpre o atendimento a aproximadamente 47 mil condenações, com gasto anual estimado em R\$ 1 bilhão. Verifica-se um dispêndio de $20 \%$ dos recursos da Saúde, com menos de $1 \%$ dos usuários ${ }^{23}$.

Segundo as informações do governo paulista, do total de receitas atendidas via ação judicial, 69\% foram emitidas por médicos da rede privada de saúde e algumas não estão ligadas a tratamentos médicos, mas, sim, a equipamentos e produtos de nutrição ${ }^{22}$.

Outro dado interessante é o levantado pela Associação da Indústria Farmacêutica de Pesquisa (Interfarma $)^{20}$, relativo ao ano 2014. Para se ter uma estimativa como exemplo, de acordo com a pesquisa, $29,7 \%$ de todo o gasto com remédios decorrente de ordens judiciais foram voltados para a compra de eculizumabe, um anticorpo importado, utilizado para tratamento de uma doença genética.

Importado, o fármaco eculizumabe custa cerca de R\$ 25 mil por dose. Como o tratamento exige 6 doses por mês, como em casos específicos de Hemoglobinúria Paroxística Noturna, a Administração Pública despende R\$ 150 mil mensais com um único paciente ${ }^{20}$.

Ressalta-se, novamente, que em muitos julgados o medicamento ainda não estava autorizado pela ANVISA. Inclusive a Advocacia Geral da União manifestou-se, na Justiça, acerca da inclusão do fármaco supracitado na lista de produtos custeados pelo $\mathrm{SUS}^{24}$.

Portanto, deve-se ter em mente que atender a todas as demandas e desejos da população em um nível ideal é impraticável, não há recursos suficientes. O dilema é: fazer o máximo para poucos - aqueles que têm maior poder de reivindicação - ou fazer o mínimo para todos? Como melhorar as escolhas do Judiciário sobre o tema?

\section{DISCUSSÃO}

\section{Perícia médico-legal como ferramenta para justiça social}

Consoante demonstrado, a judicialização da saúde é um tema que muito preocupa a Administração Pública, tendo em vista o seu contínuo crescimento, bem como as vultuosas despesas que gera.

Recentemente, o Judiciário também se mostrou ciente dos problemas oriundos da judicialização e ativismo, tanto que, por meio do Conselho Nacional de Justiça $(\mathrm{CNJ})$, criou um fórum nacional voltado para o assunto $^{25}$.

A principal aposta do CNJ é um projeto em parceria com a União para a capacitação de núcleos técnicos nos 
estados, a fim de oferecer suporte aos magistrados em suas decisões. Também se discute a implementação de varas únicas de saúde nos estados, onde, em tese, seriam alocados juízes e servidores mais preparados para lidar com essa temática.

Vê-se, portanto, que a área da capacitação técnica médica no sistema Judiciário é um tema de suma importância. Por isso que não se deve esquecer do profissional médico que, ao mesmo tempo em que cria as demandas por estes insumos e, muitas vezes, estimula o paciente a buscar na Justiça o acesso a eles, também é quem analisa tecnicamente a necessidade do referido pleito.

O discurso da insatisfação com a precariedade das decisões judiciais é apontado como uma das grandes causas da má judicialização, demonstrando a complexidade da questão da Saúde Pública no Brasil.

Frente a isso, o CNJ aponta como uma das grandes soluções a essa precariedade constatada a formação de Núcleos de Assessoria Técnica para auxiliar o juiz nas suas decisões, conforme orientado pela Recomendação $\mathrm{n}^{\mathrm{o}} 36$ de 2011.

Os núcleos em tela, compostos por médicos, farmacêuticos e outros profissionais da saúde, são resultado da busca por meios mais eficientes de assegurar a solução das demandas nascentes da assistência à saúde. Mister esclarecer que os pareceres emitidos por esta equipe técnica não substituem a atuação do juiz: apenas podem ampliar ou inclinar seu olhar sobre a situação, antes de antecipar uma tutela. Desta forma, não há que se questionar violação aos princípios constitucionais como a imparcialidade do juízo, o acesso à Justiça ou a garantia de um juiz natural ${ }^{26}$.

No mesmo sentido, frisa-se a importância do médico perito designado pelo Juízo, que durante o ato pericial pode evidenciar peculiaridades em cada caso, conjugando a análise indireta dos documentos médicos acostados aos autos com o exame clínico do Autor da demanda. Assim, muitos detalhes não constantes dos pereceres emitidos pelos Núcleos de Assessoria Técnica, pelo fato de que estes analisam questões de maneira genérica, podem ser levados em consideração durante a perícia médica oficial e mudar as conclusões, contribuindo, assim, para a decisão pelos magistrados.

Como medida capaz de desacelerar a judicialização da saúde, destaca-se a necessidade de atualização de Protocolos Clínicos e Diretrizes Terapêuticas (PCDTs) pela Comissão Nacional de Incorporação de Tecnologias no Sistema Único de Saúde (CONITEC). Ciente deste processo, a CONITEC abre, de maneira iterada, consultas públicas para manifestação da sociedade civil, especialistas e interessados, as quais visam à modernização de tratamentos e procedimentos utilizados pelo SUS, com a incorporação de novas tecnologias, medicamentos e condutas médicas. Assim, com tal atualização, e indicação de critérios diagnósticos e de tratamentos de cada doença, assim como as doses e medicamentos adequados para cada caso, haveria uma tendência à diminuição de demandas judiciais, haja vista a disponibilização de tais fármacos pelo SUS.

Além das atualizações supracitadas, tem-se dado enfoque aos medicamentos biológicos. Atualmente, o governo federal responde por cerca de $60 \%$ das compras de biológicos no País, ficando o restante a cargo dos estados e municípios. Por serem fármacos de alto custo, correspondem a $43 \%$ dos gastos do Ministério da Saúde com medicamentos, apesar de representarem 5\% da quantidade de fármacos adquirida. Dentre eles, oito medicamentos estão com patente vencida ou prestes a vencer e devem passar a ser fabricados no Brasil.

No âmbito do registro de medicamentos, foi constatado que o extenso prazo solicitado pela Agência Nacional de Vigilância Sanitária e pelo Instituto Nacional de Propriedade Intelectual, também era um fator para o aumento da judicialização da saúde. Dessa forma, os órgãos passaram a cumprir, desde 2013, prazos mais curtos para registro de medicamentos prioritários ao SUS $^{19}$.

Com o prazo estabelecido de até nove meses, surgiu a necessidade de que a ANVISA criasse uma gerência só para a análise de registro de biológicos. Também foram criadas linhas de crédito para empresas que investem em biossimilares e equipamentos - um total de R $\$ 7$ bilhões, financiados pelo Banco Nacional do Desenvolvimento, pela Financiadora de Estudos e Projetos e pelo Ministério da Saúde - que devem começar a ser fabricados ainda em $2017^{19}$.

Com a inclusão de novos fármacos pelo SUS e, ainda, a produção de tais medicações por laboratórios sediados no Brasil, a tendência será observar uma diminuição de demandas judiciais e, assim, evitar o desperdício de verba pública.

Para ilustrar o motivo de se considerar o dinheiro desperdiçado, lembra-se que os medicamentos e procedimentos adquiridos sob a pressão dos prazos judiciais são comprados de forma diferenciada, dispensando licitações, obtendo preços diferentes daqueles que poderiam ser obtidos através da compra de lotes, num processo licitatório regular.

Por fim, chama-se a atenção para o dever de que profissionais da saúde contribuam para a otimização dos serviços e insumos já ofertados pela rede pública de saúde. Marcelo Castro, Ministro da Saúde até meados de 2016, informou que foi realizada recentemente uma revisão em 51 estudos sobre judicialização que mostrou que a maioria das ações judiciais teriam sido evitadas caso tivessem sido observadas as opções terapêuticas disponíveis no Sistema Único de Saúde ${ }^{21}$, haja vista que muitas das ações que chegam ao Ministério da Saúde solicitam tratamento de doenças que já contam com 
opção terapêutica na rede pública.

\section{CONCLUSÃO}

Não é possível apontar os rumos exatos que a judicialização tomará no Brasil. $\mathrm{Na}$ área da saúde, embora ainda recente o surgimento deste fenômeno, já existem movimentos para tentar regular o papel do Judiciário. Decerto, a crescente demanda judicial nesta área exigiu dos gestores respostas que esses já estavam acostumados a omitir. Não se trata de uma generalização em relação à gestão de saúde no Brasil, mas é evidente que as recentes condições dos serviços, sobretudo para a população mais carente, são muito precárias.

Por fim, resta enfatizar a importância de estudos teóricos sobre este tema, na medida em que um olhar de fora (nem gestor, nem juiz, nem paciente) permite compreender os arranjos e rearranjos dos fatores extrajudiciais, ou seja, daquilo que está para além do processo jurídico. Identificaram-se, ao longo deste artigo, diversos atores e instituições que estão estritamente ligados a este processo; apontaram-se alguns de seus interesses e estratégias de legitimação.

A atuação dos profissionais da medicina que trabalham na interface com o direito, seja em perícias oficiais, em comitês da ANVISA e do INPI em aprovações de medicamentos, em Núcleos de Assessoria Técnica aos magistrados propostos pelo Conselho Nacional de
Justiça, mostra-se de fundamental importância para que um acesso justo à Saúde aconteça.

A construção e consolidação de comitês interinstitucionais, núcleos de assistência técnica e outras organizações correlatas pode auxiliar efetivamente na decisão dos magistrados. Aumentando, assim, a previsibilidade de gastos e a programação financeira e respeitando a regulação dos serviços (respeito a fila ou encaminhamentos próprios do SUS), garantindo então a equidade na prestação dos serviços do SUS, inclusive auxiliando na construção de um sistema de efetivação da Saúde e reduzindo a dispensa astronômica dos cofres públicos com tais demandas.

O propósito dessa iniciativa não é buscar a eliminação da judicialização da Saúde, mas expor as ferramentas disponíveis para melhorar o processo de análise de demandas que são judicializadas, como pedidos de acesso a um tratamento específico. Esse respaldo técnico também ajuda o Judiciário a prevenir fraudes envolvendo a prestação de serviços de saúde.

A próxima década será crucial tanto para o amadurecimento da atuação do Poder Judiciário nesta área, quanto para a ampliação dos direitos de cidadania e a melhoria da qualidade dos serviços do SUS. Cada dia mais, a sociedade exige que os direitos abstratos, inscritos na Constituição, materializem-se em suas vidas cotidianas, reduzindo o nível das assimetrias sociais presentes no Brasil. As estratégias para esta materialização são muitas, a judicialização é apenas mais uma delas.

Chaves O, Zerbini T. Judicialization of Medicine and the Budgetary Impact on Public Administration: A Medicolegal Approach. Saúde, Ética \& Justiça. 2017;22(2):58-65.

\begin{abstract}
This study analyzes the Judiciary's performance in the implementation of public health policies, as well as the impact of the so-called judicialization of health on the public budget. It aims to present basic aspects of the so-called judicialization of health, stressing the role of legal medicine in the phenomenon of health regulation. A bibliographical review was conducted, followed by systematization of the collected material. The research method adopted was a literature review focused on the Brazilian Judiciary's recent regulations and their impact on public health policies, considering the State's duty to promote free and universal health, as stipulated in the 1988 Constitution. Data was collected from Federal Government portals, specifically from ordinances, announcements, technical notes and judicial decisions, issued respectively by the National Council of Justice, the Ministry of Health, the Federal Attorney General and the Federal Supreme Court. The data was then analyzed. The results show that health regulation and, consequently, judicialization of health have a dramatic impact on the public health budget, to the point that, without the legal operators' advanced professional training, the health system will not be able to sustain itself for long. The research concludes that it is not possible to accurately predict the course regulation will take in Brazil. There is a tendency to provide tools for qualifying the Judiciary regarding the process of technical analysis of lawsuits that are judicialized. The contribution of legal medicine in this technical support, whether through technical reports, opinions or acting in commissions, helps the Judiciary to prevent fraud involving the provision of health services, thus optimizing the expenditure of public coffers arising from judicial activism.
\end{abstract}

KEY WORDS: Right to Health; Judicial Decisions; Public Health Policy.

\title{
REFERÊNCIAS
}

1. Brasil. Presidência da República, Casa Civil, Subchefia para Assuntos Jurídicos. Constituição da República Federativa do Brasil de 1988 [Internet]. Brasília, DF; 1988. [acesso em
2017 jun. 27]. Disponível em: http://www.planalto.gov.br/ ccivil_03/constituicao/constituicaocompilado.htm

2. Biehl J, Socal MP, Amon JJ. The judicialization of health and 
the quest for accountability: Evidence from 1.262 lawsuits for access to medicines in Southern Brazil. Health Hum Rights. 2016; 18(1):209-20.

3. Conselho Nacional de Justiça. Núcleo técnico produz notas em 100 causas de saúde em 6 meses no AP [Internet]. Brasília; 2017 [acesso em 2017 jun. 27] Disponível em: http://www. cnj.jus.br/noticias/judiciario/84911-nucleo-tecnico-produznotas-em-100-causas-de-saude-em-6-meses-no-ap

4. Conselho Nacional de Justiça. Conselho aprova nova resolução para reduzir judicialização da saúde [Internet]. Brasília; 2016 [acesso em 2016 set. 19]. Disponível em: http://www.cnj.jus.br/noticias/cnj/83333-conselho-aprovanova-resolucao-para-reduzir-judicializacao-da-saude

5. Conselho Nacional de Justiça [Homepage na Internet]. Brasília. Disponível em: http://www.cnj.jus.br

6. Brasil. Ministério da Saúde [Homepage na Internet]. Brasília. Disponível em: http://portalsaude.saude.gov.br

7. Advocacia Geral da União [Homepage na Internet]. Brasília Disponível em: http://www.agu.gov.br

8. Brasil. Supremo Tribunal Federal [Homepage na Internet]. Disponível em: http://www.stf.jus.br

9. Silva JA. Aplicabilidade das normas constitucionais. $7^{\mathrm{a}}$ ed. São Paulo: Malheiros Editores; 2008. p.140.

10. São Paulo. Procuradoria Geral do Estado de São Paulo (PGE). Convenção Americana de Direitos Humanos [Internet]. San José de Costa Rica; 1969 [acesso em 2017 jun. 27]. Disponível em: http://www.pge.sp.gov.br/centrodeestudos/ bibliotecavirtual/instrumentos/sanjose.htm

11. Brasil. Presidência da República, Casa Civil, Subchefia para Assuntos Jurídicos. Decreto n⿳50991, de 6 de julho de 1992. Atos Internacionais. Pacto Internacional dos Direitos Econômicos, Sociais e Culturais. Promulgação [Internet]. Brasília; 1992 [citado 2017 jun. 27]. Disponível em: http:// www.planalto.gov.br/ccivil_03/decreto/1990-1994/d0591. htm

12. Brasil. Presidência da República, Casa Civil, Subchefia para Assuntos Jurídicos. Decreto ${ }^{\circ}$ 99.710, de 21 de novembro de 1990. Promulga a Convenção sobre os Direitos da Criança [Internet]. Brasília; 1990 [acesso em 2017 jun. 27]. Disponível em: http://www.planalto.gov.br/ccivil 03/ decreto/1990-1994/d99710.htm

13. Gazzola LPL. Observatório Judiciário sob a ótica do Direito à Saúde: repensando sua dimensão processual e a aplicação de precedentes judiciais [Dissertação]. Belo Horizonte: Universidade Federal de Minas Gerais, Faculdade de Direito; 2014.

14. Barroso LR. Judicialização, ativismo judicial e legitimidade democrática. Revista de Direito do Estado (RDE). 2009; 13:71-91.

15. Silva JA. Aplicabilidade das Normas Constitucionais. $5^{\mathrm{a}} \mathrm{ed}$ São Paulo: Malheiros Editores; 2001. p.115.

16. Mello C. Discurso proferido na posse do Ministro Carlos Ayres Britto como Presidente do Supremo Tribunal Federal, em 19/04/2012 [Discurso] [Internet]. Brasília; 2012 [acesso em 2017 jul. 07]. Disponível em http://www.stf.jus.br/ arquivo/cms/noticiaNoticiaStf/anexo/DiscursoCM.pdf
17. Pepe VL, Figueiredo Tatiana A, Simas L, Osorio GS, Ventura M. A judicialização da saúde e os novos desafios da gestão da assistência farmacêutica. Ciênc saúde coletiva. 2010;15(5):2405-14. DOI: http://dx.doi.org/10.1590/S141381232010000500015

18. Brasil. Ministério da Saúde. Portal da Saúde. Ações judiciais impactam em até 7 bilhões de reais no SUS, diz ministro [Internet]. Brasília; 2016 [acesso em 2017 jun. 11]. Disponível em: http://portalms.saude.gov.br/noticias/ agencia-saude/25275-ministro-da-saude-fala-sobreimpacto-de-acoes-judiciais-no-sus

19. Brasil. Ministério da Saúde. Portal da Saúde. Ministério da Saúde vai investir R\$ 35 bilhões em produção de medicamentos até 2016 [Internet]. Brasília; 2015 [acesso em 2016 nov. 30]. Disponível em : http://portalsaude.saude. gov.br/portalsaude/noticia/10405/162/ministerio-da-saudevaiinvestir-r\%24-35-bi-ate-2016.html

20. Berta R. União prevê gasto recorde com tratamentos por ordem judicial [Internet]. O Globo. 2016 jul. 24 [acesso em 2017 fev. 20]. Disponível em: http://oglobo.globo.com/ brasil/uniao-preve-gasto-recorde-com-tratamentos-porordem-judicial-19774203

21. Brasil. Ministério da Saúde. Portal da Saúde. Em cinco anos mais de $\mathrm{R} \$ 2,1$ bilhões foram gastos com ações judiciais [Internet]. Brasília; 2016 [acesso em 2017 fev. 20]. Disponível em: http://portalsaude.saude.gov.br/index. $\mathrm{php} /$ cidadao/principal/agencia-saude/20195-em-cinco-anosmais-de-r-2-1-bilhoes-foram-gastos-com-acoes-judiciais

22. Estado de São Paulo. Governo do Estado de São Paulo. Secretaria da Saúde. SP cria ofensiva para combater 'judicialização' da Saúde [Internet]. São Paulo; 2016 [acesso em 2017 fev. 20]. Disponível em: http://www.saude.sp.gov. br/ses/noticias/2016/abril/sp-cria-ofensiva-para-combaterjudicializacao-da-saude

23. Estado de São Paulo. Secretaria de Estado da Saúde de São Paulo. Gabinete do Secretário .Judicialização em Saúde no Estado de São Paulo. In: II Jornada de Direito à Saúde; 2015. São Paulo: Tribunal de Justiça de São Paulo; 2015.

24. Advocacia Geral da União. Afastada incorporação de medicamento sem registro da Anvisa no SUS por falta de comprovação da eficácia [Internet]. Brasília; 2013 [acesso em 2017 fev. 20]. Disponível em: http://www.agu.gov. $\mathrm{br} /$ noticia/afastada-incorporacao-de-medicamento-semregistro-da-anvisa-no-sus-por-falta-de-comprovacao-daeficacia--2

25. Brasil. Poder Judiciário. Conselho Nacional de Justiça. Portaria 8, de 02 de fevereiro de 2016. Cria o Comitê Organizador do Fórum Nacional do Poder Judiciário para monitoramento e resolução das demandas de assistência à saúde [Internet]. Brasília; 2016 [acesso em 2017 mar. 20]. Disponível em: http://www.cnj.jus.br/files/conteudo/arquivo /2016/07/7416acb59c746525fd9f278a5d7719b9.pdf

26. Ramos KA, Ferreira ASD. Análise da demanda de medicamentos para uso off label por meio de ações judiciais na secretaria de estado de saúde de Minas Gerais. Rev Dir Sanitário. 2013;14(1):98-121. DOI: http://dx.doi. org/10.11606/issn.2316-9044.v14i1p98-121 